\title{
Accommodation Status and Gender Based Analysis at Public Universities in Tanzania: Case of Ardhi University
}

\author{
Isabella Wilfred Mtani, Said Nuhu \\ Institute of Human Settlement Studies, Ardhi University, Dar es Salaam, Tanzania \\ Email: mtanibell@hotmail.com, mgolewasu@gmail.com, sanutelaky@yahoo.com
}

How to cite this paper: Mtani, I.W. and Nuhu, S. (2019) Accommodation Status and Gender Based Analysis at Public Universities in Tanzania: Case of Ardhi University. Open Journal of Social Sciences, 7, 24-41.

https://doi.org/10.4236/jss.2019.74003

Received: November 26, 2018

Accepted: April 5, 2019

Published: April 8, 2019

Copyright ( 2019 by author(s) and Scientific Research Publishing Inc. This work is licensed under the Creative Commons Attribution International License (CC BY 4.0).

http://creativecommons.org/licenses/by/4.0/

\begin{abstract}
Higher education institutions in Tanzania like many other developing countries are facing various challenges. Among other things, the increase of enrollments, does not comply with quantity of accommodations in public universities. Both male and female students have been impacted by inadequate accommodation. Thus, this study is aiming at examining which sex is highly vulnerable to the scarcity of in-campus accommodation. Mixed methods were employed in this study with a combination of survey questionnaire and in-depth interview. Questionnaire was the mainly employed instrument used to collect data from the selected students. Apart from that, an in-depth interview was employed to collect data from the key informants including staff from the Dean of Student's Office (DoSO) coupled with measurement and observations to determine rooms quality and sizes. The findings indicate that there is a yearly increase in student's enrollment: and cumbersome loans and registration procedures which, aggravated students' accommodation problems. Moreover, the houses rented by off-campus students have no reflection to the student's requirements and financial capability. Overall, the study disclosed that female students are highly affected by the inadequacy of on-campus accommodation as compared to their male counterparts. This situation potentially makes them vulnerable to health and social related problems, which affects in a great extent their academic performance. The paper recommends that the government through its public universities should involve private investors in constructing more halls and hostels to accommodate the increasing demand of student hostels and to intervene in the search for proper off-campus accommodation for students.
\end{abstract}

\section{Keywords}

Off-Campus Accommodation, Public University, Students, Gender, In-Campus 
Accommodation

\section{Introduction}

For years higher education becomes an economic promoter to the society at the same time giving out personal benefits [1]. It intrinsically generates and establishes a productive citizen, increasing society value and attending both a public and private good-gives to society and potential to individuals respectively [2]. For the society and individual development, higher education is a key by increasing society awareness to address development challenges of nations. Reference [3] highlighted higher education as a "chief impetus for national development". Universities are engines for economic growth committed to building a skilled workforce [4]. Having knowledge on the above mentioned facts, Government and individuals are currently taking education seriously by ensuring children are receiving better education up to the university level.

Consequently, the number of students pursuing studies at the higher learning institutions has been increasing, and it is estimated that it will double in 2025 [5] [6]. Nearly all of this increase will be in the less developed countries (LDCs) [7]. Educational policies in LDCs have been advocating for a need to increase the number of students' enrollment, but such enrollment does not cope with the learning and living facilities [8]. In LDCs, there are plenty of stories on the shortage of university accommodation [9]. According to student housing report by JLL real estate firm in 2016 the demand for new purpose-built student accommodation across Sub-Saharan Africa was set to exceed 500,000 beds over the next five years [10]. Among other things, scholars [7] [9] [10] have argued that student accommodation is a critical challenge to most public universities in the LDCs and Sub-Saharan Africa in particular.

In many countries, especially in LDCs, governments have been the main providers of student accommodation in public higher education institutions [7]. As a result of limited resources, governments are unable to adequately meet the accommodation demand for all public higher institutions [6]. Over the past two decades, governments in many developing countries have involved private hostel providers to participate in building hostels and halls of residence for students in order to meet the demand for more accommodation infrastructure [11]. This has attracted many private individuals into investing in student hostel accommodation.

Inadequate accommodation for students has remained one of the critical challenges faced by public universities in Tanzania as indicated by [12] [13], and [8]. In fact, apart from the Dodoma University in Dodoma region, other public universities in Tanzania have a limited number of rooms in their halls of residence and are seeking loans for the construction of the new ones. The issue of students' residence should not be undermined or neglected by students, teach- 
ers, parents, policy makers and administrators of educational systems [14]. This may largely be contributed by the fact that student's accommodation in public universities has more value than housing students and their belongings.

Student's accommodation problem is a growing one that led to many studies on the same because it is an educational input that contributes to the academic performance of students [16]. These studies are focused on assessment of either its direct effect on academic performance or student's satisfaction [16]. On performance it's either living on or off the campus. Findings from [14] [17], and [18] emphasize that students who live on-campus were more involved in-campus life, had a lower dropout rate, and perform at a higher academic level than off-campus students. In support of the aforesaid, [19] and [20] noted that living off-campus is more challenging and hence negatively impact academic performance.

Academic performance and student's satisfaction are well researched and interrelated whereby the later affects academic performance if inadequately achieved [20]. Other authors indicated that spatial quality and size, rent, safety and security affects student's satisfaction in a great extent ([5] [20] [21], and [22]). Others are hygiene [23], location distance and issue of territoriality, thermal comfort as well as noise level [24].

Different gender groups are differently affected by the absence of hostels and possibly their coping strategies also differ [25]. The study by [26] indicates the disable student both male and female are impacted more by deficit of student hostel, while [27] argues the existing physical infrastructure does not favour the disable student in public University on one hand. On the other hand, it is acknowledged that male and female student also have been impacted differently regardless of disabilities, their degree of specialization, economic and social status. Nevertheless, not enough information was provided in literature on to what extent are the sex groups affected. Therefore, the aim of this paper is to provide information on the status and situation of accommodation deficit in a public university in Tanzania and establish the sex that has been impacted more by the absence of proper accommodation.

\section{Methodology}

The study was done in Ardhi University and its surrounding areas. The University is highly growing in terms of student enrolment and establishment of new schools and departments. Mixed method employed to collect both primary and secondary data on the gender impacts of inadequate accommodation quality on student academic performance at Ardhi University. The method is used in order to get a complete picture of the accommodation problem in relation to gender in public universities in Tanzania. Self-administered questionnaires were deployed as main instruments for collecting data from a sample of 480 respondents consisting of 200 in-campus and 280 off-campus students both divided in half, male and female students. The students were selected using random and stratified 
sampling techniques. The information on how the students could be accessed were provided by the Hostel Manager with respect to their school of registration. Off-campus students were randomly and stratified selected from their areas of residents based on their accommodation status and schools of registration. This was a major target group that provided important information for the study.

A number of 20 key informants participated in in-depth interviews and were selected purposively. Ten (10) participants composed ARU staff and 10 private house owners. The selection of ARU staff was based on various criteria including; staff members whose daily activities relates to students' accommodation and students' welfare; have had a considerable knowledge on the effect of accommodation shortage on the academic performance of students. The house owners were randomly selected from areas adjacent to the University presumed to be preferred by students for living. These areas included Mlalakuwa, Survey, Makongo, Changanyikeni and Sinza. Direct field observation was used in the study. The method was employed in order to observe various activities and academic life of students especially those residing off-campus and identified those events that adversely affect students' academic progress. The observation aimed to assess the living conditions of rooms in halls of residents and rented rooms off the campus in relation to student's academic performance.

Document reviews were also employed to complement other techniques. This technique helped to read and review various policies related to higher education; student's enrolment and accommodation in general. The Ardhi University Accommodation Policy of 1999 and University Charter were reviewed in order to understand their contribution on student accommodation and its impacts. The analysis of collected data was done manually using tables, graphs and other basic statistical tools of summarizing the information.

Measurements of physical aspects such as, functional spaces in rental houses and widths of streets and passages supported our analysis of spatial quality in relation to academic life. Photographs were systematically taken to document relevant indoor real-life situations and outdoor spatial qualities, particularly in relation to quality of neighborhood safety and security, hygiene and accessibility.

The data obtained though questionnaires and participant observation were thematically analyzed. Due to qualitative nature of this study, the data analysis was basically in the form of narratives. Quantitative analysis was only used using inferential statistics in order to support the narratives, hence capture the meaning of data.

\section{The Results}

\subsection{Enrolment of Student by Sex at the Ardhi University (ARU)}

The results obtained from documentary review within ten (10) years of existence of ARU (i.e. 1996-2006) show that the then University College of Lands and Architectural Studies (UCLAS) increased the number of undergraduate academic programmes from six (6) to thirty nine (39) during the period. As a result 
of these changes, students' enrolment increased from only 400 in 1996 to about 1400 in 2007. When UCLAS became a fully-fledged university Schools were established. Student's enrollment increased to 1537 undergraduate students in academic year 2008/2009. Student's population steadily rose to 4107 in the academic year 2015/16. Of these, 1492 (36.3\%) were females while 2615 (63.7\%) were male students. Surprisingly, the hostels for undergraduate students at ARU have remained the same in terms of number and capacity/size to accommodate students. To this end, only $530(12.7 \%)$ of undergraduate students get accommodation. The shortage of students' accommodation has further been magnified by the fact that there has been a consistent expansion of student enrolment following the increase in the number of academic programmes. These scenarios are depicted in Table 1.

\subsection{Student Accommodation Status at Ardhi University by Sex}

As of 2016/2017, the Ardhi University had a total population of 4068 undergraduate students (Figure 1) of whom males were 2522 (62\%) while females were 1546 (38\%). As already hinted earlier on, ARU has the capacity to accommodate only $530(12.7 \%)$ of the undergraduate students population, whereas $232(9.2 \%)$ are males and $286(18.5 \%)$ are females (Table 2). Worth emphasizing, student's accommodation needs at ARU will continue to grow with the expansion of student enrolment. On one hand, ARU has been growing in terms of quantitative indicators signaled by a steady increase in the number of student's enrollment. Tragically, the increase has not been concurrently matching with the expansion

Table 1. Yearly students' enrollment by sex.

\begin{tabular}{cccc}
\hline & \multicolumn{2}{c}{ Sex } & \multirow{2}{*}{ Total Students } \\
\cline { 2 - 3 } Years & Female & Male & 845 \\
\cline { 2 - 3 } $2004 / 05$ & 165 & 955 \\
\hline $2005 / 06$ & 180 & 1051 \\
$2006 / 07$ & 207 & 1122 \\
$2007 / 08$ & 228 & 1212 \\
$2008 / 09$ & 319 & 1481 \\
$2009 / 10$ & 519 & 1926 \\
$2010 / 11$ & 725 & 2187 \\
$2011 / 12$ & 1008 & 2393 \\
$2012 / 13$ & 1156 & 2459 \\
$2013 / 14$ & 1208 & 2343 \\
$2014 / 15$ & 1357 & 2615 \\
$2015 / 16$ & 1492 & 2522 \\
$2016 / 2017$ & 1546 & \\
\hline & & 253 \\
\hline
\end{tabular}

Source: [28]. 
of halls of residence. Currently, the criteria for room allocation at ARU is as indicated on Table 3.

\subsubsection{Criteria Used in the Allocation of Rooms}

As per the ARU student accommodation policy, the findings indicate that the criteria used in room allocation include: disability, health status of the student, position in student organization, year of study, sex and degree programme. The study quantified the criteria used in room allocation using the parameters indicate on Table 3: The findings show that despite the fact that ARU has been striving to ensure that all vulnerable groups are considered for in-campus accommodation, still some of the students belonging to these groups are left out to search for the alternative accommodation elsewhere outside the university campus due to shortage of hostels. This situation occurs because from 2011, ARU has witnessed an upsurge in the number of female students relative to the common "tradition" of enrolling female students. Table 3 indicates that the score points outlined in the accommodation policy is no longer realistic.

\subsection{Characteristics of the In-Campus Accommodation}

The findings indicate that, all hostel rooms in-campus are $3 \mathrm{~m} \times 3 \mathrm{~m} \times 2.7 \mathrm{~m}$ big in volume, enough light, enough ventilation, $100 \%$ indoor comfort if well utilized and is provided with enough shared toilet. Nonetheless, the university

Table 2. Available spaces in halls of residents.

\begin{tabular}{cccccc}
\hline \multicolumn{2}{c}{ Available space by sex } & \multicolumn{2}{c}{ Student Population 2017} & \multicolumn{2}{c}{ Accommodated \% } \\
\hline Space for Male & 238 & Male & 2522 & Male & 9.2 \\
Space for female & 292 & Female & 1546 & Female & 18.5 \\
\hline
\end{tabular}

Source: Dean of Student's Office, 2017.

Table 3. Criteria for room allocation.

\begin{tabular}{cc} 
Criteria & Scores \\
\hline Students with disabilities & 14 \\
First year female students & 14 \\
First year foreign students & 12 \\
First year male students & 12 \\
Female continuing students & 11 \\
ARUSO President, Vice President, Prime Minister, Speaker, Minister \\
for Accommodation, peer counselors and ARUSO Cabinet. \\
Male students in programmes which require students to \\
stay long hours in-campus after normal classes \\
Other male students \\
Total
\end{tabular}

Source: [29]. 
hostel has encountered some challenges caused by overpopulation. Initially, the rooms were designed for a maximum of two students and on top of that, the rooms had two wardrobes, two single beds, and two working tables. Nevertheless, due to the increase in student's population, the number had doubled to four students per room. To accommodate this number, the two single beds were replaced with two bunk beds. Other supporting services such as toilets, power and sewage were not redesigned to cater for the increase in the number of students. This situation has endangered students' hygiene, security and retard their academic efficiency as highlighted by [30]. To mitigate the challenges, students have resorted to taking turns in using the fewer facilities available in the rooms compared to the increase in the demand of those facilities.

\subsection{Characteristics of the Off-Campus Accommodation}

\subsubsection{Location Preference}

Students prefer to live closer to the university, apparently in order to save time and costs associated with living far away from the university. Furthermore, the affordability of rental accommodation is the other reason determining student's preferences on where to live. Students mostly prefer cheaper and affordable rooms with suitable payment conditions and flexibility in paying and changing of residents. About $54 \%$ of the house owners meet these conditions in order to attract students. Yet, $46 \%$ of the house owners claimed flexibility in changing the rooms of residency was associated with problems especially among male students who bring in new mates without consulting the house owner, leading to frequent theft cases. The flexibility of paying also attracts graduates who wish to keep those rooms in the neighborhood. The preferred neighborhood areas are indicated in Table 4.

\subsubsection{Safety}

The findings indicated that the surrounding neighborhoods are not environmentally friendly to off-campus students. It was observed that in the neighborhood there are drug-addicted street gangs, thereby making the whole neighborhood areas unsafe especially during the night. Students who were staying off-campus

Table 4. Preferred neighborhoods by students.

\begin{tabular}{ccc}
\hline Preference & Neighborhood name & Distance $(\mathbf{k m})$ \\
\hline $1^{\text {st }}$ & Survey & 0.6 \\
$2^{\text {nd }}$ & Makongo & 1.5 \\
$3^{\text {rd }}$ & Mpakani & 0.8 \\
$4^{\text {th }}$ & Mlalakuwa & 1.2 \\
$5^{\text {th }}$ & Lufungira & 1 \\
$7^{\text {th }}$ & Changanyikeni & 2.5 \\
$8^{\text {th }}$ & Sinza & $2.0-2.7$ \\
\hline
\end{tabular}

Source: Google map (2017). 
raised the issue of security. They argued that when on their way to off-campus accommodations, they were frequently been attacked by robbers and thieves who hide themselves in the narrow paths waiting for people to attack (Figure 1 \& Figure 2). During the interview, one of the female students lamented that:

"The pathway from the university to our residence has been extremely dangerous for us. There are robbers who became a threat not only to our property but also to our lives. Justifying that, in the past two months, we have witnessed 3 death cases in the area. We are not safe at all especially during the night. For this reason, we are forced to return early, hence cannot stay late in-campus for discussions or working on our projects".

The argument raised by the female students resonates with other arguments raised by on-campus students who said:

"My friend who stays off-campus called a police immediately when he realized that two people were trying to break into his room, one through the door and the other through the window. These thieves intended to steal his laptop and his mobile phone. The thieves ran away after becoming aware that there was somebody in the room".

The two arguments from students indicate that off-campus accommodations are not safe for students, particularly female students who are vulnerable to crimes like rape and theft.

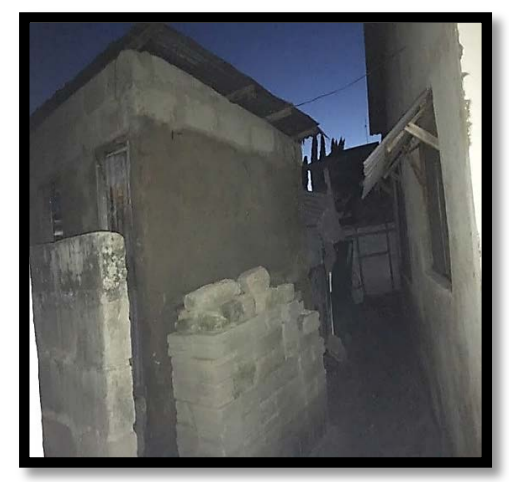

Source: Fieldwork.

Figure 1. A congested housing.

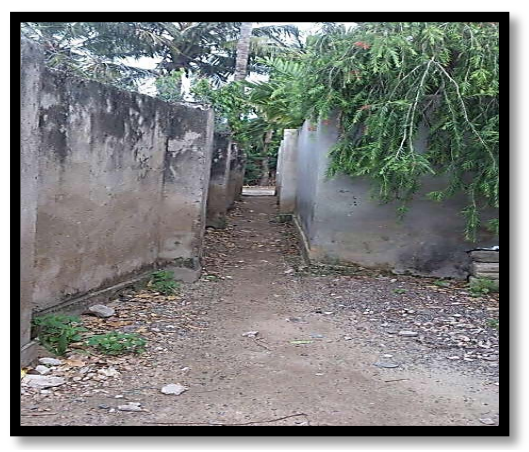

Source: Fieldwork.

Figure 2. A trace pass road to off-campus accommodation. 


\subsubsection{Room Size and Hygiene}

Generally, off-campus rented rooms were not in ideal condition for studying. Quantitative figures revealed that about $56 \%$ of the 80 rooms observed had $3 \mathrm{~m}$ $\times 2.5 \mathrm{~m} \times 2.2 \mathrm{~m}$ volume, no enough light, poorly ventilated and lacked indoor comfort (Figure 3). The room sizes had adverse impacts on the students who desperately needed to finish their project after lecture hours. Too many activities were being performed in the same rooms and provided no space for self-studying. Clarifying on that, from biological point of view, female students need more bedroom space as compared to their male counterparts. For the case of students, $85 \%$ females and $28 \%$ males' students like to cook their own food. The cooking itself is performed in the sleeping room (Figure 4). This is not

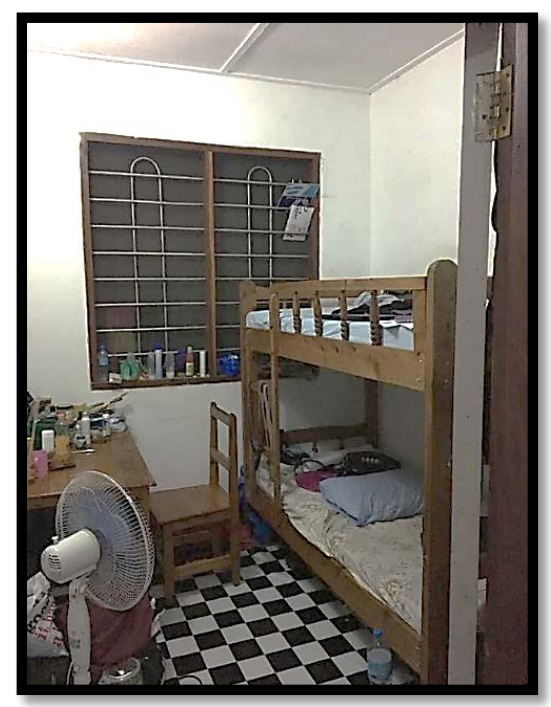

Source: Fieldwork.

Figure 3. A congested off-campus room.

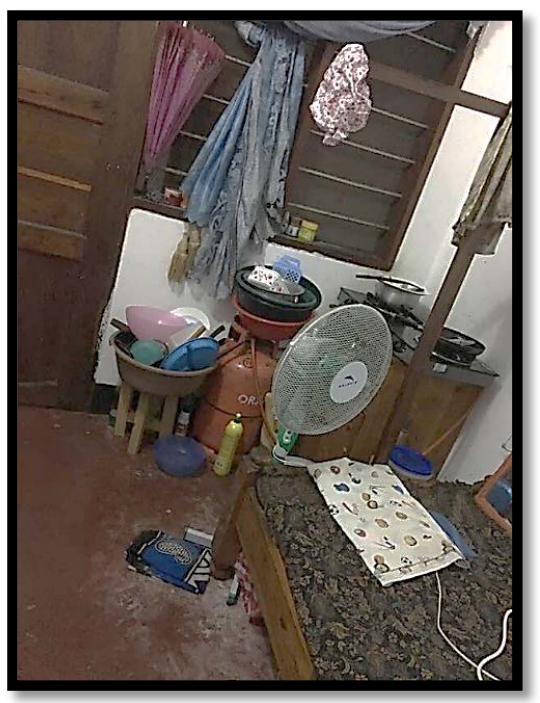

Source: Fieldwork.

Figure 4. Indoor cooking. 
healthy and can trigger fire disaster risks.

The rooms are provided with unhygienic-shared toilets and catalyzed communicable diseases like Urinary Tract Infection (UTI). UTI has been common among female students. It has become among the main reasons apart from malaria that make female students miss lectures. Persistence of airborne diseases is related to congestion in rented rooms and hostels (Figure 5). As far as diseases were concerned, during the interview, one student was quoted saying:

"My staying here has been disastrous. I was diagnosed with UTI three times during the last Semester"

\subsubsection{Cost of Living}

The findings indicate that on-campus accommodation was cheap compared to the off-campus (Table 5). Considering the amount of loan received from the government, it would not be possible for students to finance their life in off-campus accommodation. This explains why $55 \%$ of the male students were being forced to work in the informal sector, while $30 \%$ of the female and $55 \%$ of the male students had resigned to new alternative ways of managing their survival

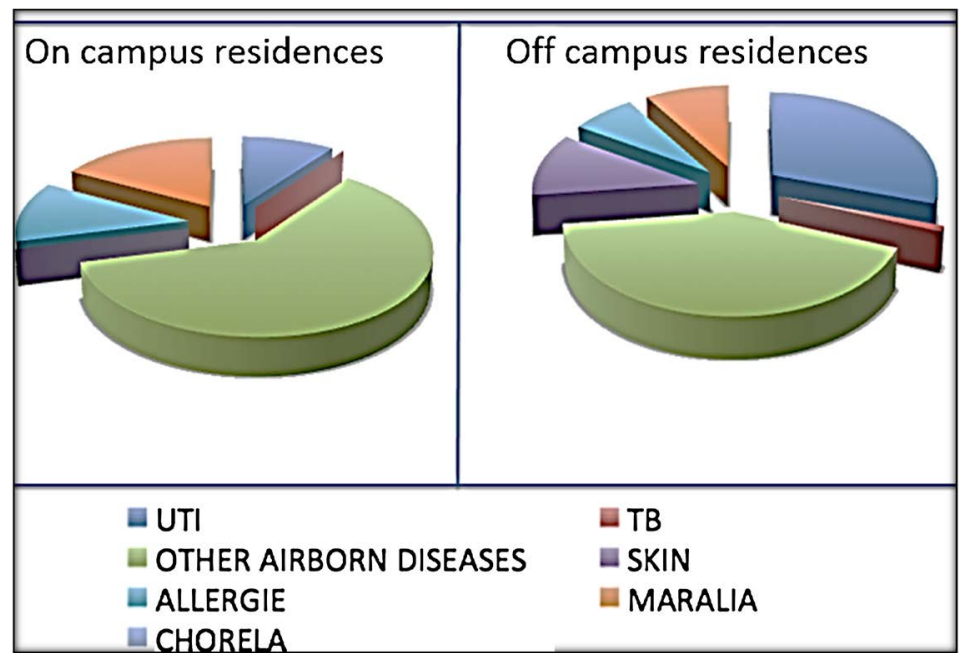

Source: [31].

Figure 5. Disease distribution in relation to status of the accommodation.

Table 5. Comparison of cost between on-campus and off-campus.

\begin{tabular}{ll}
\hline \multicolumn{1}{c}{ On-Campus } & \multicolumn{1}{c}{ Off-compass } \\
\hline - Payment procedures once per semester (4 months. & - Payment procedures six months in \\
equivalent to 112,500 TZS) & advance (ranges between 420,000 to \\
- No utility bills & 900,000 TZS) \\
- Furnished rooms & - Extra utility bills \\
- No transport costs & - Unfurnished rooms \\
- No cleaning cost & - Transport cost \\
& - Cleaning cost including cost of garbage \\
& collection \\
\hline
\end{tabular}

Source: Fieldwork. 
means, including prostitution or other immoral behaviour. These are socially unethical behaviour, but some of the off-campus students were lured into accepting them in order to cater for the extra costs incurred on rental accommodation. Thereupon, these mitigating factors reduce the time required by student to concentrate on their studies.

Other challenges include the noise pollution from bars and nightclubs to off-campus neighborhoods; poor sewerage systems where by on site sewers are drained on access roads; congestion and lack of social amenities (Figure 6 \& Figure 7). Combination of the aforesaid characteristics seemed to have created un-conducive learning environment.
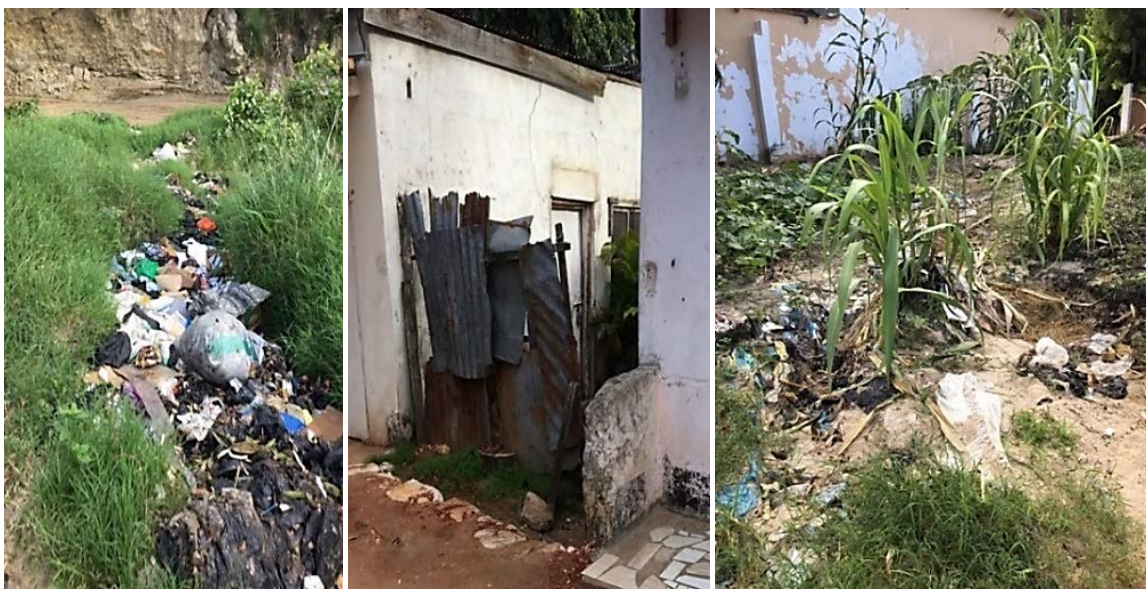

Source: Fieldwork.

Figure 6. Surrounding environment near to off-campus student residence.

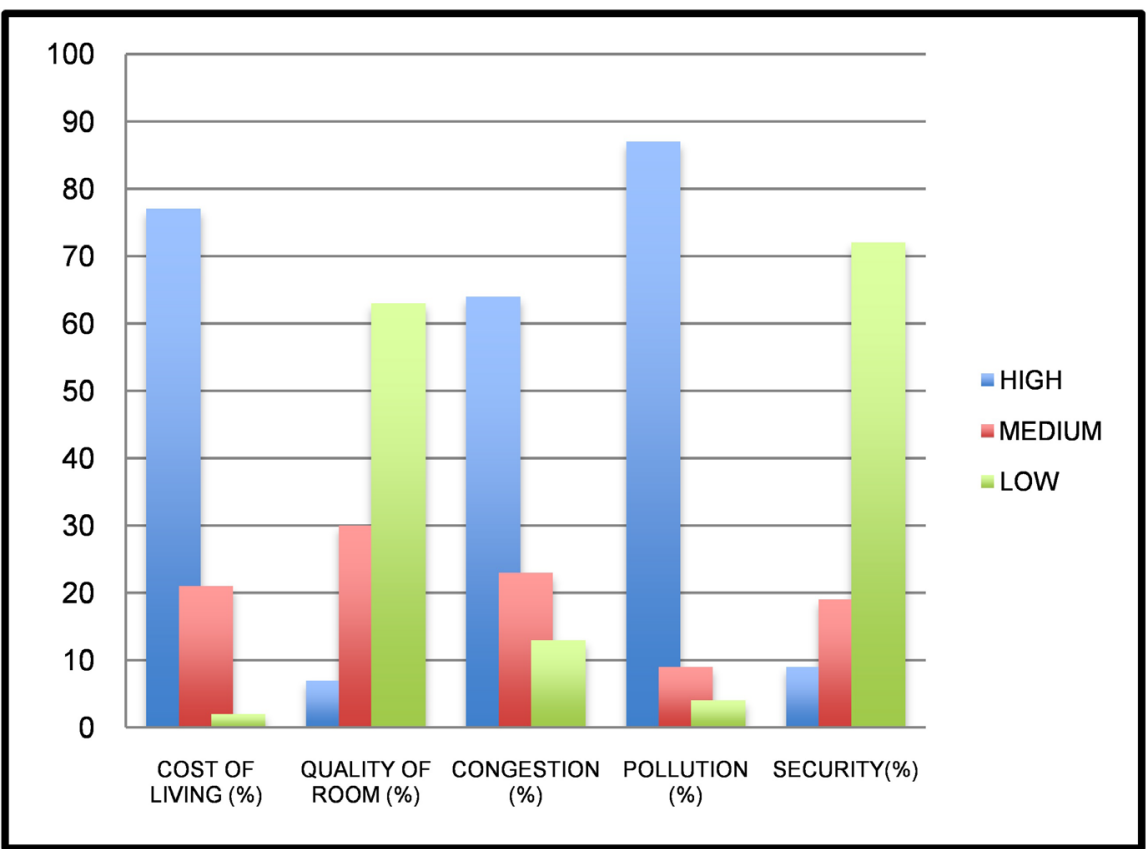

Source: Fieldwork data.

Figure 7. Off-campus neighborhood characteristics. 


\subsection{Student and Accommodation: Who Are More Affected?}

The findings revealed that lack of the on-campus accommodation differently impacted on gender groups. While $67 \%$ female students could not work on their projects after classes at the university because they feared for their safety back to their off-campus rooms, $88 \%$ male students were capable of working long night hours at the University without any fear of being attacked on their way back to their off-campus accommodation. Instead, approximately $72 \%$ of female and $52 \%$ of male students were highly affected by the high costs of living outside the campus. Again, $62 \%$ female and $33 \%$ male students were affected by the noise pollution. Moreover, $80 \%$ female and $77 \%$ male students were not well secured in off-campus rooms. Additionally, $87 \%$ female and $67 \%$ male students were vulnerable to communicable diseases. More to say, $73 \%$ female and $21 \%$ male students had social problems with the families in which they we living. The reasons for drop out among the males were related primarily with lack fund to support their academic life, while female drop out was related to poor performance due to combination of social factors (lack of funds, prostitution, rape, safety and security etc.) and the living environment.

\subsection{Discussion}

The aspect of students accommodation based on gender in public universities of Tanzania has been a subject of research. To that effect, a number of researchers have addressed this controversial topic, these include: [5] [32] and [33]. These scholars contend that public universities in Africa face shortage of accommodation, therefore, students find alternative accommodation outside or around the university campus. Despite the increase in the number of private firms engaged in bridging the gaps of shortage of student accommodation, in-campus accommodation is still a problematic issue.

Globally, there has been an increase in the number of students' enrolment in higher learning institutions [34] [35]. This is because in the last decades, many countries have been investing on high education and also emphasizing the access to education as part of the basic rights [36]. Globalization and the development of science and technology have led to the emergence and introduction of new academic programmes and encourage more students to join the universities [37]. Reference [35] has reported that the rate of students' enrolment has increased from $14 \%$ to $32 \%$ in two decades.

Besides, it has been noted that there has been higher enrolment at the higher learning education in countries such as China, India, US and Brazil [38]. Nonetheless, the increase in the enrolment has not been matching with the existing student accommodation. Having enough accommodation is a critical important issue, which should be considered by any responsive university [34]. He also noted that having quality and good accommodation or housing promotes the psychological gratification and leisure. Further, [5] [18] [39], and, [40] closely linked the absence or availability and the qualities of accommodation to stu- 
dents' academic performance.

Despite the problem of fewer student accommodations, still, universities tend to enroll more students than should otherwise been the case [37] [41], and [42] distinguished that South Africa faced student accommodation crisis while the government and the university in particular were not finding the new alternative to deal with the problem. Reference [43] also came up with similar findings indicating that in Tanzania, despite the fact that the current government has started constructing new hostels in the University of Dar es Salaam, nothing has been done if comparison is made with the existing demand of students' accommodation. He added that the University of Dar es Salaam has been increasing students' enrolment each academic year while the number of students' hostels has remained unchanged.

To ensure the proper allocation of the existing student accommodation, universities have developed different criteria used in room allocation. These criteria include: disabilities, student organization leaders, first year students and foreign student [28]. In Tanzania, universities have different accommodation policies but with some striking commonalities. Taking the Muhimbili University of Health and Allied Sciences (MUHAS) as a case in point, students with special medical care needs, and continuing female and male students from upcountry and student in clinical year are prioritized [44].

It is also noted by [45] that even the rooms and hostels are not user friendly for some of the groups, which are given the priority for room allocation. Additionally, some of the rooms and hostels lack facilities for disabled people and they are characterized by poor public transport [45]. The infrastructure around the hostels e.g. toilets, bathrooms, stairs and narrow paths are also not good to allow easy movement of the disabled [27].

According to [46] the accommodation challenges faced by universities have led to many students opting for off-campus accommodation. Nonetheless, the off-campus environments are generally not good for students' life and academic performance [46] [47]. In most of the developing countries, the surrounding environment are characterized by crimes, insecurity, noise, theft and poor public transport, particularly in those universities located in the big cities [48]. Therefore, off-campus students often face these challenges. Likewise, [48] have pointed out that in the University of Johannesburg, students faced transport challenges. They use more time waiting for transport and travelling from the halls of residence. Off-campus rooms and facilities also are not user friendly for students, especially those who are taking engineering, medical and science courses [14].

It is also noted that off-campus life is more expensive compared to in-campus. For instance, the payment for renting a room, water, electricity as well as cleaning services of the surrounding environment is considerably high. The situation is better for in-campus students, they happen to enjoy some of the services like cleaning services surrounding the environment since these are usually catered 
for by the institution in question. However, despite the challenges they face in this type of accommodation hostels are affordable [9]. Supportively, [46] added that in South Africa in-campus students easily access the existing and free facilities provided by their institutions compared to off-campus students. He insisted that it is easy to form social and discussion groups as well as attending different gatherings organized by the university even in the evening hours for in-campus students. Equally importantly, staying off-campus impacts more the female students than the male counterparts. Confirming that [14] have reported that off-campus female students have been facing multifaceted personal/psychological, social, economic, and educational problems. They also noted that for female students, getting a room or an apartment outside the university was a tough job. This is because the house owners prefer to rent their houses to male students than the females [14]. Reference [9] brings to attention that a similar situation is faced in Uganda and particularly at Makerere University, where the female students who stay off-campus encounter a lot of challenges. The challenges include inability to attend evening courses or using the extra time in the library, insecurity (such as robbery) and rape. Students have also been engaging in immoral activities in order to get money, which could make them afford very high living and accommodation payment [9]. Reference [15] also raised similar arguments that in Kenya, female students who stay off-campus are more exposed to Gender Based Violence (GBV) and Sexual Harassment (SH) which sometimes impacts their career and health. In a similar note, [49] have recommended measures to address GBV and SH for female students (both in-campus and off-campus) for the purpose of providing safer environment in most African universities.

\section{Conclusions}

This paper hereby concludes that lack of accommodation has forced students to work in the informal sector in order to afford the extra cost incurred on rental accommodation. The size of congested rooms also had negative repercussions on those students who were struggling to complete their project after lecture hours, for they have neither space for putting desks nor chairs. The study has also established that unhygienic condition of the off-campus rooms escalates the chance of contacting diseases and forces students to miss lectures frequently. On that premise, one can confidently conclude that characteristics of off-campus neighbourhood adversely affect students socially and academically.

These situations eventually reduce student's time and concentration on their studies. It is evident from the study that female students (especially first year) are more vulnerable due to lack of in-campus accommodation than their male counterparts. This situation leads to unwanted pregnancies; premature and unwanted relationships; increased rate of female student drop-out; poor academic performance; and increased risks of contracting Sexual Transmitted Diseases (STDs). Suggestions for improvements include a pro-active government intervention in provision of halls of residence and hostels, together with involvement 
of private investors in helping to resolve the problem.

\section{Conflicts of Interest}

The authors declare no conflicts of interest regarding the publication of this paper.

\section{References}

[1] Giroux, H.A. (2002) Neoliberalism, Corporate Culture, and the Promise of Higher Education: The University as a Democratic Public Sphere. Harvard Educational Review, 72, 425-463. https://doi.org/10.17763/haer.72.4.0515nr62324n71p1

[2] Morley, L., Leach, F. and Lugg, L. (2009) Democratising Higher Education in Ghana and Tanzania: Opportunity Structures and Social Inequalities. International Journal of Educational Development, 29, 56-64. https://doi.org/10.1016/j.ijedudev.2008.05.001

[3] Hood, M. (1988) Tanzania after Nyerere. Pinter Publishers Limited, London.

[4] Osaikhiuwu, O.C. (2014) Institutional Factors Affecting the Academic Performance of Public Administration Students in a Nigerian University in Public Administration Research. Canadian Center of Science and Education, 3, 171-177.

[5] Nimako, G.S. and Bondinuba, F.K. (2013) An Empirical Evaluation of Student Accommodation Quality in Higher Education. European Journal of Business and Social Sciences, 1, 164-177.

[6] URT (1999) United Republic of Tanzania Higher Education Policy, Ministry of Science, Technology and Education. February 1999.

[7] Maslen, G. (2012) Worldwide Student Numbers Forecast to Double by 2025. University World Wide News, Issue No. 209. http://www.universityworldnews.com

[8] Istoroyekti, Y.M. and Hum, S.S. (2016) Issues Challenging Universities: A Case of Tanzania Higher Education. Ahmad Dahlan Journal of English Studies, 3, 51-62. https://doi.org/10.26555/adjes.v3i1.3625

[9] Sawyerr, A. (2004) Challenges Facing African Universities: Selected Issues, African Studies Review. Cambridge University Press, Cambridge, 1-59.

[10] Chibelushi, W. (2017) Should You Invest in African Student Housing? Issues of Africa Business Review. http://www.africanbusinessreview.co.za

[11] Centre for Global Education (2002) Rich world, Poor World: A Guide to Global Development. https://www.cgdev.org/files/2844_file_EDUCATION1.pdf

[12] Sundkvist, H. (2010) Students Housing in Urban Areas of Tanzania a Comparison Study of Student's Housing in Dar es Salaam and Iringa and Its Affect's on Student's Performance in Higher Education. http://www.diva-portal.se

[13] JLL (2016) Student Housing: A New Asset Class in Sub-Saharan Africa. http://www.africa.jll.com

[14] Tesfaye, S., and Jibat, N. (2014) Situational Assessment of Off-Campus Resident Female Students of Jimma Teacher Training College (JTTC) In Focus, Oromia. European Scientific Journal, 10, 238-250.

[15] Ndung'u, J.M. (2015) Status of Private Accommodation for Undergraduate Students in Kenya: A Case of Kenyatta University. Unpublished Master's Thesis, Kenyatta University, Kenya.

[16] Maina, J.J. and Aji, J.Y. (2017) Influence of Accommodation on the Academic Per- 
formance of Architecture Students. Built Environmental Journal, 14, 47-59.

[17] Araujo, P. and Murray, J. (2010) Channels for Improved Performance from Living on Campus. American Journal of Business Education, 3, 57-64.

[18] Addai, I. (2013) Problems of Non-Residential Students in Tertiary Educational Institutions in Ghana: A Micro-Level Statistical Evidence. Journal of Emerging Trends in Educational Research and Policy Studies, 4, 582-588.

[19] Ekeijuba, P. (2015) The Running of Hostels as Auxiliary Services in University of Benin: Implications for Academic Studies. African Education Research Journal, 3, 51-54.

[20] Mathew, I.A. (2014) The Challenge of Being a Student of Any Public Tertiary Institution in Nigeria of Today. Journal of Studies in Education, 4, 128-141.

https://doi.org/10.5296/jse.v4i1.1261

[21] Modebelu, M.N. and Agommuoh, P.C. (2014) Environmental Hazards and Hostel Accommodation Problems: Challenges for University Education in Nigeria. US-China Education Review, 4, 407-413.

[22] Nchungo, J. (2013) Factors Affecting Students' Academic Performance: A Case Study of the University of Zambia Main Campus. Unpublished BA Thesis, University of Zambia, Lusaka, Zambia.

[23] Yusuff, O.S. (2011) Students Access to Housing: A Case of Lagos State University Students-Nigeria. Journal of Sustainable Development, 4, 107-122. https://doi.org/10.5539/jsd.v4n2p107

[24] Amole, D. (2012) Gender Differences in User Responses to Students Housing, Asia Pacific International Conference on Environment-Behaviour Studies, Grand Margherita Hotel, Kuching, Sarawak, Malaysia, 7-9 December 2010. Social and Behavioral Sciences, 38, 89-99.

[25] McGregor, K.K., Langenfed, N., Horne, V.S., Oleson, J., Anson, M. and Jacobson, W. (2016) The University Experiences of Students with Learning Disabilities. Learning Disability Research and Practical, 31, 90-102.

https://doi.org/10.1111/ldrp.12102

[26] Kabuta, G.L. (2014) Problems Facing Students with Physical Disabilities in Higher Learning Institutions in Tanzania. Unpublished Master's Thesis, The Open University of Tanzanian, Dar es Salaam, Tanzania.

[27] ARU Fact and Figures (2004-2017).

[28] Ardhi University Accommodation Policy (1999).

[29] Oladiran, O.J. (2013) A Post Occupancy Evaluation of Students Hostels Accommodation. Journal of Building Performance, 4, 33-43.

[30] ARU Dispensary (2017) Disease Database for Ardhi University Community, Unpublished Database.

[31] Nimako, G.S. and Bondinuba, F.K. (2013) Relative Importance of Student Accommodation Quality in Higher Education. Current Research Journal of Social Sciences, 5, 134-142.

[32] Yakaboski, T. and Birnbaum, M. (2013) The Challenges of Student Affairs at Kenyan Public Universities. Journal of Student Affairs in Africa, 1, 33-48.

[33] Bondinuba, F.K., Nimako, S.G. and Karley, N.K. (2013) Developing Student Housing Quality Scale in Higher Institutions of Learning: A Factor Analysis Approach. Urban Studies Research, 2013, Article ID: 383109.

http://dx.doi.org/10.1155/2013/383109 
[34] University of Oxford (2017) International Trend of Higher Education 2016-2017, Part One New Developments in International Higher Education. University of Oxford, Oxford.

[35] Gordon, J.S. (2013) Is Inclusive Education a Human Right? Journal of Law, Medicine and Ethics, 41, 754-767.

[36] Matsolo, J.M., Ningpuanyeh, W.C. and Susuman, S. (2016) Factors Affecting the Enrolment Rate of Students in Higher Education Institutions in the Gauteng Province, South Africa. Journal of Asian and African Studies, 53, 63-80.

[37] Sharma, Y. (2012) Fast Pace of Higher Education Enrolment Growth Predicted to Slow, Issue No. 213. http://www.universityworldnews.com

[38] Oluwaseyi, O.B. (2015) The Effects of Students' Housing on Academic Performance at the University of Ibadan in Nigerian. International Journal of Scientific and Engineering Research, 6, 1118-1132.

[39] Weinhard, F. (2014) Social Housing, Neighborhood Quality and Student Performance. Journal of Urban Economics, 82, 12-31. https://doi.org/10.1016/j.jue.2014.06.001

[40] Kim, H.W. and Lee, J. (2016) The Effect of Accommodation on Academic Performance of College Students with Disabilities. Rehabilitation Counseling Bulletin, 60, 40-50. https://doi.org/10.1177/0034355215605259

[41] Savills (2017) World Student Housing: The Global Search for Scale. http://pdf.euro.savills.co.uk/global-research/world-student-housing-2017-18.pdf

[42] Mathebula, S. (2017) South Africa Students Faces Accommodation Crisis at Universities, News 24. https://www.news24.com

[43] Tungaraza, E. (2017) Hostels a Big Problem in Higher Education. The Citizens, Dar es Salaam, Tanzania.

[44] Muhimbili University of Health and Allied Sciences (2015) Student Accommodation Guidelines. Muhimbili University of Health and Allied Sciences, Dar es Salaam, Tanzania.

[45] Oke, A.E., Aigbavboa, O.C. and Raphiri, M.M. (2017) Students' Satisfaction with Hostel Accommodations in Higher Education Institutions. Journal of Engineering, Design and Technology, 15, 652-666.

[46] Muslim, M.H., Karim, A.H. and Abdullah, I.C. (2012) Satisfaction of Students' Living Environment between On-Campus and Off-Campus Settings: A Conceptual Overview. Procedia-Social and Behavioral Sciences, 68, 601-614. https://doi.org/10.1016/j.sbspro.2012.12.252

[47] Muslim, M.H., Karim, A.H. and Abdullah, I.C. (2012) Challenges of Off-Campus Living Environment for Non-Resident Students' Well-Being in UiTM Shah Alam. Procedia-Social and Behavioral Sciences, 50, 875-883. https://doi.org/10.1016/j.sbspro.2012.08.089

[48] Mbara, T. and Celliers, C. (2013) Travel Patterns and Challenges Experienced by University of Johannesburg Off-Campus Students. Journal of Transport and Supply Chain, 7, Article No. a114.

[49] Peretomode, V.F. and Ugbomeh, A.N. (2013) Problems Faced by Undergraduate and Diploma Students and Their Survival Strategies in Nigeria: An Institutional Analysis. International Journal of Educational Planning and Administration, 3, 25-33. 


\section{Attachment 1-Questionnaire}

\begin{tabular}{|c|c|c|c|c|c|}
\hline $\mathrm{S} / \mathrm{N}$ & QUESTIONS & ANSWERS & & & REMARKS \\
\hline 0 & Where do you live (Please name a place ) & & & & \\
\hline 1 & $\begin{array}{l}\text { Please mention your sex; your school and program of } \\
\text { registration, and year of study. }\end{array}$ & & & & \\
\hline 2 & How do you rate the University accommodation? & Good & $\square$ Best & & \\
\hline 3 & What do you like about your room general? & & & & \\
\hline 4 & What do you dislike about your room in general? & & & & \\
\hline \multirow[t]{5}{*}{5} & How comfortable is your room in terms of: & & & & \\
\hline & - Temperature/Ventilation & Hot & C Cool & Very cool & \\
\hline & - Lighting & Poor & Below average & Average & \\
\hline & & Good & Excellent & & \\
\hline & - Size & $\begin{array}{l}\text { Very much } \\
\text { Quite adequ }\end{array}$ & $\square$ Inadequate & Adequate & \\
\hline
\end{tabular}

6 Who do you live with?

7 What do you dislike and like about your neighbourhood and/or room in general?

8 What do you dislike and like about your room in general?

9 How comfortable is your room in terms of:

- Temperature/Ventilation

$\begin{array}{ll}\square \text { Hot } & \square \text { Warm } \square \text { Cool } \square \text { Very cool } \\ \square \text { Poor } & \square \text { Below average } \\ \square \text { Good } & \square \text { Average }\end{array}$

- Size

$\square$ Very much

$\square$ Adequate

10 How do feel about your bedroom as a place for studying?

How much do you pay for a room per month?

12 Is there any extra cost apart from room rent?

13 How safe is your neighbourhood

14 Who financed your living here in this neighbourhood?

15 Where would you rather live on campus? In this neigbourhood?

16 Why do you choose to live in this neighborhood?

17 How do you rate the following

- Quality of your room

- No of occupants against room size

- Pollution level of noise and dust

- Neighborhood Safety and Security

18 What else do you consider as appropriate for your accommodation?

19 How comfortable and useful is your room in relation to:

- Resting

- Working on your university projects

- Studying

- Doing assignment

$\begin{array}{lll}\square \text { High } & \square \text { Medium } & \square \text { Low } \\ \square \text { High } & \square \text { Medium } & \square \text { Low } \\ \square \text { High } & \square \text { Medium } & \square \text { Low } \\ \square \text { High } & \square \text { Medium } & \square \text { Low } \\ \square \text { High } & \square \text { Medium } & \square \text { Low }\end{array}$

